\title{
EFFECT OF SWD IN THE MANAGEMENT OF PELVIC INFLAMMATORY DISEASE (PID)
}

\author{
SHOMA FK ${ }^{1}$, MAHMOOD $\mathrm{K}^{2}$, HOSSAIN MS $^{3}$
}

\begin{abstract}
Pelvic inflammatory disease (PID) is one of the most frequent causes of pelvic pain which causes suffering of female patients during their reproductive period. PID causes major medical, social and economic problems. Long term sequelae like ectopic pregnancy, infertility are common and their management is expensive. Medical treatment of PID should be immediate because sequelae are more frequent if the treatment is delayed or inadequate. The large majority of PID patients can be managed satisfactorily with conservative method of treatment which consists of rest for a sufficient length of time, drug for relief of pain, antibiotic, mild to moderate amount of exercise and Short Wave Diathermy (SWD). In this experimental study a total 70 patients aged between 18 years to 40 years of chronic PID were included from September 2007 to February 2008 in the Department of Physical Medicine \& Rehabilitation, DMCH, Dhaka. Patients were randomly divided into two groups, experimental group (group-A) were treated with antibiotic, exercises, Short Wave Diathermy (SWD), Activities of daily living instruction ( $A D L)$ and control group (group-B) underwent antibiotic, exercises, $A D L$.Clinical improvements were observed throughout the whole treatment period in both groups. The differences of improvement between the groups were not observed up to 11 days but the significant difference of improvement was observed on day 14 and also at day 60. Therefore, in PID use of SWD, as adjunctive therapy along with conventioal management is effective.
\end{abstract}

Keywords: Pelvic inflammatory disease (PID), Short Wave Diathermy (SWD), Efficacy.

J Dhaka Med Coll. 2011; 20(2) : 178-182.

\section{Introduction}

Pelvic inflammatory disease (PID) is one of the most frequent causes of pelvic pain which causes suffering of female patients during their reproductive period. As a lady of $3^{\text {rd }}$ world country women' are mostly illiterate, communication facilities are very poor, health facilities are not easily available and costly, so people are not aware of their health problems. Consequently these cases remain undiagnosed and untreated for years together.PID is an upper genital tract infection predominantly involving the endometrium and fallopian tubes. ${ }^{2}$ Many cases are silent or subclinical. The disease burden of PID in developing countries remains enormous. ${ }^{1}$ PID causes major medical, social and economic problems. Long term sequelae like ectopic pregnancy, infertility are common and their management is expensive. Medical treatment of PID should be immediate because sequelae are more frequent if the treatment is delayed or inadequate. ${ }^{2}$ There are many risk factors of PID. The large majority of patients can be managed satisfactorily with conservative method of treatment which consists of rest for a sufficient length of time, drug for relief of pain, antibiotic, mild to moderate amount of exercise and Short Wave Diathermy (SWD). SWD may be defined as the current that alternate with a very high frequency of oscillations of a million or more per second. Heat can be produced inside the tissues, which is the principal physical effect of high frequency current. The main physiological effect of diathermy is due to rising of the temperature along the course of its passage. ${ }^{6}$ Pelvic inflammatory disease presents a serious problem for the practicing physician and the radiologist who is called to determine the origin and extent of the inflammatory process. Pelvic infection may mimic clinically other inflammatory process. ${ }^{3}$ In our country there are many PID patients who do not respond

1. Dr. Farzana Khan Shoma, Assistant Professor, Department of Physical Medicine, BIHS Hospital

2. Dr. Khurshid Mahmood, Assistant Professor, Department of Physical Medicine, DMC

3. Dr. Md. Shahadat Hossain, Assistant Professor, Department of Physical Medicine, DMC

Correspondence : Dr. Farzana Khan Shoma, Assistant Professor, Department of Physical Medicine, BIHS Hospital 
to antibiotic only. There are some literatures in relation to PID. In those studies PID was treated with antibiotic, exercise and Short Wave Diathermy. But it is not scientifically examined. So I have tried to observe the effect of SWD on PID.SWD is one of the indications of PID treatment in many books ${ }^{4,5}$, 6 With all possible searches, a few studies on the effect of SWD in the management of PID were available. In this study, an attempt has been made to observe the effectiveness of Short Wave Diathermy on the management of PID and to evaluate the effectiveness of treatment by SWD to a group of people having PID and compare the result with a similar group without having any treatment with SWD and also to see the demographic pattern, risk factors and clinical pattern of PID patients.

\section{Materials and Methods:}

This randomized experimental study was carried out from September 2007 to February 2008 in the Department of Physical Medicine \& Rehabilitation, Dhaka Medical College Hospital, Dhaka. During this period total 70 patients aged between 18 years to 40 years of chronic PID were included in the study. Patients were randomly divided into two groups, experimental group (group-A) were treated with antibiotic, exercises, Short Wave Diathermy (SWD), Activities of daily living instruction (ADL) and control group (group-B) underwent antibiotic, exercises, ADL .Levofloxacin, 500mg orally once daily group for 14 days with Metronidazole $500 \mathrm{mg}$ orally twice a day for 14 days were given to all patients. Isometric back muscle exercise and Pelvic floor muscle exercise along with activities of daily living instructions were given to all patients. Only in experimental (group-A), SWD was applied to pelvic region for 15 minute for 14 days at a frequency of 27.33 megacycles (wave length of 11 meters).All the patients were assessed initially and at 3 days interval for 14 days. Final evaluation was done after 8 weeks follow up.Main outcome parameters were Pains score, Tenderness index (lower abdominal tenderness), Visual analogue scale (VAS).Collected data was analyzed by using SPSS package for Windows (Version 12). The results were expressed as mean \pm SD and the level of significance was expressed by $p$ value unless otherwise stated. Student's ' $t$ ' tests were done to see the level of significance.

\section{Results}

Among the study patients the mean age in group-A was $28.31 \pm 5.55$ years and in group B was 25.26 4.84 years. Among the study population $(\mathrm{n}=70)$ highest number of patients $56(80 \%)$ had history of MR. The next common risk factors of the patients who had history of multiple sexual partner $7(10 \%)$. Other common risk factors of the patients who had history of D \& $\mathrm{C}$ and IUCD insertion. (Table-I)

\section{Table-I}

Risk factors distribution of the patients with PID $(n=70)$

\begin{tabular}{lcc}
\hline Risk factors & No. of patients & Percentage \\
\hline MR & 56 & 80 \\
Multiple sexual partner & 7 & 10 \\
D, E \& C & 5 & 7.14 \\
IUCD & 2 & 2.85 \\
\hline
\end{tabular}

In this study maximum number of patients $51(72.85 \%)$ were in poor class, $43(61.42 \%)$ patients lived in kacha house, 51 (72.85\%) patients only passed below primary level, 53 $(75.71 \%)$ were housewife.In this study 25 $(35.71 \%)$ patients had 4 children, $22(31.41 \%)$ had 3 children, $9(12.85 \%)$ had 2 children, $7(10 \%)$ had 1 children and $3(4.28 \%)$ had no children. The distribution of PID is increasing with number of parity.In this series $70(100 \%)$ patients had lower abdominal pain, $51(72.85 \%)$ patients had per vaginal discharge, $43(61.42 \%)$ patients had dyspareunia, $13(18.57 \%)$ patients had low grade fever and $7(10 \%)$ patients had vomiting.

In group- $A$, significant Improvement $(\mathrm{p}<0.05)$ in every 3 days was observed during the whole treatment period up to 14 days and significant Improvement $(p<0.05)$ was also observed after 60 days follow up.In group-B, significant Improvement $(\mathrm{p}<0.05)$ in every 3 days was observed during the whole treatment period up to 11 days but significant Improvement $(\mathrm{p}<0.05)$ was not observed after 14 days and 60 days follow up.Significant improvement $(p<0.05)$ were observed throughout the whole treatment period in both groups. The differences of improvement between the groups were not observed up to 11 days but the significant difference of improvement was observed on day 14 and also at day 60. 
Table-II

Comparative treatment response between Group- $A$ ( $n=35)$ and Group- $B(n=35)$

\begin{tabular}{lcccccc}
\hline Group & $\mathrm{D} 0$ & $\mathrm{D}-4$ & $\mathrm{D}-7$ & $\mathrm{D}-11$ & $\mathrm{D}-14$ & $\mathrm{D}-60$ \\
\hline Group-A & $8.46 \pm 2.61$ & $7.89 \pm 2.610$ & $7.40 \pm 3.274$ & $7.00 \pm 3.008$ & $5.80 \pm 2.805$ & $05.97 \pm 2.25$ \\
Group-B & $7.49 \pm 2.201$ & $8.17 \pm 2.717$ & $8.00 \pm 2.461$ & $7.20 \pm 2.564$ & $7.29 \pm 2.966$ & $7.40 \pm 3.21$ \\
P value & .097 & .655 & .389 & 1.000 & 0.035 & 0.036 \\
$95 \%$ CI & $-.182-2.125$ & $-1.556-.98$ & $-1.982-0.78$ & $-1.983-.782$ & $-2.863-.109$ & $-2.757-.100$ \\
\hline
\end{tabular}

\section{Discussion}

In the present study, 3.67 percent of all patients in the department of Physical Medicine \& Rehabilitation DMCH, Dhaka presented with PID. In 2007 among all patients in gynae out patient department 35\% had PID (Record of Gynae outpatient department 2007).A detailed and methodical study of 70 cases in this study showed highest $(32.85 \%)$ distribution of this disease being in the age group of 25-30 years. Peterson HB et al. ${ }^{10}$ mentioned that women with PID were usually under the age of 25 years. Shah HN et al. ${ }^{11}$ showed in his study that 87 percentage of the patient were between the age group of 20-35 years. Tarafder $\mathrm{S}^{7}$ showed the highest incidence $(55.21 \%)$ of PID in the age group of 26-35 years. The age groups of these studies coincided with our study. This also indicates that young groups are more sufferers. A number of risk factors have been linked to PID including history of MR, multiple sexual partner, D\&C, IUCD users. Laila $\mathrm{TR}^{8}$ showed that $54.66 \%$ of her patients had history of MR. Sultana $\mathrm{S}^{9}$ showed that $72.2 \%$ of the patients had history of MR and $13.33 \%$ patients had termination of pregnancy by $\mathrm{D} \& \mathrm{C}$ and $9 \%$ patients had multiple sexual partners. Tarafder $\mathrm{S}^{7}$ showed that $66.13 \%$ of her patients had history of MR. Kocher $\mathrm{M}^{12}$ showed that the highest incidence of pelvic infection occurred following termination of pregnancy. It is estimated that 36-53 million termination of pregnancy are performed through out of the world of which 21 million are unsafe. ${ }^{13}$ In FIGO manual on family planning ${ }^{13}$, it is stated that IUCD use is associated with an increase risk of PID estimated to be 1.5-10 fold for IUCD users compared to other methods of contraceptives. In our study $80 \%$ of patients had history of MR, $10 \%$ had history of multiple sexual partners,
7.14\% had history of D\&C and $2.85 \%$ had history of IUCD users. This figures correlates with Sultana $\mathrm{S}^{9}$ study. Laila $\mathrm{TR}^{8}$ showed that $68 \%$ patients in her study were from lower socioeconomic condition, $28 \%$ from middle class and only $4 \%$ from higher class. Tarafder $\mathrm{S}^{7}$ showed $49.48 \%$ patients were from lower socioeconomic status and Sultana $\mathrm{S}^{9}$ mentioned $45 \%$ patients from lower, $20.6 \%$ patients from middle socioeconomic status.In our study highest number of patients $(72.85 \%)$ came from poor socioeconomic condition followed by lower middle class $(20 \%)$, upper middle class (4.28\%) and rich (2.85\%). From the above study, it is difficult to draw a conclusion of the relationship between socioeconomic status and PID because only certain classes of patients lower or middle class usually attend this hospital. Higher socioeconomic classes rarely come to a government hospital. Regarding residence 43(61.42\%) patients in our study reside in kacha house and they lived in slum area because of low socioeconomic condition. As the slum people did not maintain their personal hygiene properly and usually suffered from malnutrition their clinical manifestations were more. Sultana $\mathrm{S}^{9}$ showed that $65 \%$ patients lived in slum area, $21 \%$ patients lived in pakka building. The present study showed that the majority $(72.85 \%)$ of women were illiterate, $28.85 \%$ of them had primary level of education and others had secondary education or above.Tarafder $\mathrm{S}^{7}$ showed that $51.05 \%$ patients were illiterate and rests were educated at primary, secondary or higher level. Sultana $\mathrm{S}^{9}$ showed that only $12.9 \%$ of her patients were educated up to secondary school or above and $51.3 \%$ were illiterate, $35 \%$ had primary level of education.Laila $\mathrm{TR}^{8}$ showed that majority $(69 \%)$ 
of her patients were illiterate, $24 \%$ had primary level of education; only $7 \%$ had secondary education or above. These findings are comparable with our study. Overall situation can be improved by educating this women.In this study the distribution of PID increases with the number of parity as we saw that the highest number of patients (25) had four children and 22 patients had 3 children. This result indicates that repeated child birth is an important risk factor for the development of PID. So proper family planning measures can reduce the incidence of PID.Laila TR ${ }^{8}$ showed that $56 \%$ patients were multipara, Tarafder $\mathrm{S}^{7}$ showed $83.85 \%$ of the patients in her study were multipara, Sultana $\mathrm{S}^{9}$ showed $81.7 \%$ patients were multipara. Peterson HB et al. ${ }^{10}$ showed that PID occurred mostly in multipara. Westrom $\mathrm{L}^{13}$ showed $74.4 \%$ of the PID cases were multipara. These studies therefore focused that in the developing countries patients were mostly parous women and in industrialized countries the majority were younger multiparous women. Present study showed that $75.71 \%$ patients were house wife. Laila $\mathrm{TR}^{8}$ showed that $90 \%$ of the patients were house wife and $10 \%$ were in service. Sultana $\mathrm{S}^{9}$ showed $83.4 \%$ patients were house wife and $16.6 \%$ were service holder.In needs more extensive studies with large population and different occupation group to establish the epidemiology of PID.In this study $100 \%$ patients present with lower abdominal pain for 5 months to 5 years duration, the presenting complaints of $72.85 \%$ patients were per vaginal discharge which is mild or moderate in amount, $61.42 \%$ patients were presented with dyspareunia.Low grade fever was the other constitutional symptom found in 13 cases. 10 percent patients presenting complaints was vomiting. 54 patients complained with low back pain.In order of the frequency and intensity, the major symptoms of Laila $\mathrm{TR}^{8}$ study were found lower abdominal pain in $100 \%$ cases, backache $53.3 \%$, vaginal discharge $56 \%$, dyspareunia $60 \%$ and low grade fever in 5\%.Tarafder $\mathrm{S}^{7}$ showed the common clinical findings were lower abdominal pain $95.31 \%$, backache $64 \%$, and dyspareunia $78.12 \%$.Sultana $\mathrm{S}^{9}$ showed lower abdominal pain $100 \%$, backache $98.3 \%$, vaginal discharge $84 \%$ cases, dyspareunia $84.2 \%$ cases. Kocher $\mathrm{M}^{12}$ study showed that lower abdominal pain was the most commonly reported symptom.Laila $\mathrm{TR}^{8}$ showed that $100 \%$ cases had tenderness of lower abdomen. Sultana $S^{9}$ showed that $53.6 \%$ patients had tender lower abdomen.In our study showed that $84.28 \%$ patients had tenderness of lower abdomen, $80 \%$ patients were malnourished. The findings of present study are competent with other studies.Probably the most interesting features that emerged from this study was the effect of SWD on PID. Usually PID was managed with antibiotic therapy but sign symptoms were not completely resolved with antibiotic alone. There are some literatures in relation to PID. In those literatures PID was treated with antibiotic, exercise and SWD. But it is not scientifically examined. In this study it was tried to observe the effect of SWD on PID. Improvement were observed throughout the whole treatment period in both groups. The difference of improvement between the groups were not observed up to 11 days but the significant difference of improvement was observed on day 14 and also at day 60. In this study, after 14 days treatment and after 60 days follow up significant improvement $(\mathrm{P}<0.05)$ was observed in Group A. This indicates that Short Wave diathermy (SWD), antibiotic, exercise with ADL advice are effective in the management of chronic PID.

\section{Conclusion}

Considering the findings of the present study and the studies previously done by others, it can be concluded that additional SWD is more effective in reducing the symptoms of pelvic inflammatory disease (PID). Therefore, in PID use of SWD, as adjunctive therapy along with conventioal management is effective. As the numbers of patients studied were very small, the information collected needs verification by larger studies.

\section{References}

1. Paavonen J. Pelvic inflammatory disease. Medicine 2005; 33; 10: 43-46.

2. European Journal of Obstetrics and Gynecology and Reproductive Biology 2000; 92: 189-192. 
3. Blume J, Peripert JF, Ness RB, et al. Clinical Predictors of endometritis in women with symptoms and signs of pelvic inflammatory disease. Am J Obstet Gynecol 2001; 184: 856863.

4. Dutta DC. Pelvic infection. In text Book of Gynaecology. 4th edition, New central Book Agency (P) Ltd. Calcutta, India, 2007; 118-127.

5. European Journal of Obstetrics and Gynecology and Reproductive Biology 2000; 92: 189-192.

6. Blume J, Peripert JF, Ness RB, et al. Clinical predictors of endometritis in women with symptoms and signs of pelvic inflammatory disease. Am J Obstet Gynecol 2001; 184: 856863.

7. Jacobson L, Westrom L. Objectivized diagnosis of acute pelvic inflammatory disease. Am J Obstet Gynecol 1969; 105: 1088-1098.
8. Taipale $\mathrm{P}$, Tarjanne H, Ylostalo P. Transvaginal sonography in suspected pelvic inflammatory disease. 1995; Ultrasound Obstet Gynecol 6: 430-434.

9. Munday PE. Clinical aspects of pelvic inflammatory disease. Hum Reprod 1997; 12(11Suppl): 121-126.

10. Chronic pelvic pain. http://www.mayoclinin com / health / chronic-pelvic-pain / DS00571/ DSECTION=1. Download date- 15-12-2007.

11. Gjelland K, Ekerhood E, Grandberg S. Transvaginal ultrasound guided aspiration for treatment of tubo-ovarian abscess: a study of 302 cases. Am J Obstet Gynecol 2005; 193: 1323-30.

12. Laila TR. Result. Study of 192 cases of chronic PID in GOPD of Dhaka Medical College Hospital, Dissertation BCPS 1997; 73-92.

13. Heisterberg L. Factors influencing spontaneous, dyspareunia, dysmenorrhoea and pelvic pain, obstet gynaecol 1993; 81: 594-5. 